\title{
Bone Mineral Density as a Predictor of Atherosclerosis and Arterial Wall Stiffness in Obese African-American Women
}

\author{
Samy I. McFarlane Ghazanfar Qureshi Gagandeep Singh \\ Kinda Venner-Jones Louis Salciccioli Jason Lazar \\ Division of Cardiology, State University of New York Downstate Medical Center, \\ Brooklyn, N.Y., USA
}

\section{Key Words}

Bone mineral density $\cdot$ Osteoporosis $\cdot$ Atherosclerosis $\cdot$ Wave reflection $\cdot$ Aortic stiffness

\begin{abstract}
Bone demineralization is associated with higher cardiovascular event rates, possibly due to vascular calcification and accelerated atherosclerosis. African-Americans have less bone loss and less calcium content within atherosclerotic plaques. However, whether loss of bone mass is related to atherosclerosis has not been examined in African-Americans. The objective of this study was to evaluate possible associations between bone mineral density (BMD), carotid intimal-medial thickness (CIMT), and arterial stiffness. We studied 100 obese African-American women (BMI: $26.6 \pm 6.2$; age: $63 \pm 14$ years) referred for BMD estimation by dual-energy X-ray absorptiometry scan. BMD $\left(\mathrm{g} / \mathrm{cm}^{2}\right)$ was obtained at the lumbar spine (L1-L4), femoral neck, and total hip. Arterial stiffness was evaluated by the heart rate-corrected augmentation index (AI@75) and pulse wave velocity (PWV) using applanation tonometry. CIMT was measured by vascular ultrasound. Mean CIMT, AI@75, and PWV were $0.72 \pm 0.14 \mathrm{~mm}, 28.8 \pm 9.0 \%$, and 8.9 $\pm 1.6 \mathrm{~m} / \mathrm{s}$, respectively. Mean BMD values at the lumbar spine, femoral neck, and hip were 0.96 $\pm 0.19,0.80 \pm 0.16$, and $0.91 \pm 0.17 \mathrm{~g} / \mathrm{cm}^{2}$. Older subjects had higher CIMT $(r=0.61, p<0.001)$ and Al@75 ( $r=0.42, p<0.001)$. There was a significant correlation between Al@75 and CIMT $(r=0.45, p<0.001)$. BMD was negatively correlated with Al@75 (lumbar: $r=-0.22, p=0.03$; femoral neck: $r=-0.24, p=0.01$; hip: $r=-0.21, p=0.03$ ). BMD was unrelated to CIMT (lumbar: $r=-0.09, p=0.42$; femoral neck: $r=-0.15, p=0.17$; hip: $r=-0.13, p=0.23)$. On multivariate analysis, age $(p<0.001)$, hypertension ( $p=0.02)$, and lumbar $B M D\left(p=0.01, R^{2}=0.30\right)$ were independent predictors of increased Al@75 after adjusting for age, height, and cardiovascular risk
\end{abstract}




\section{CardioRenal Medicine}

\begin{tabular}{l|l}
\hline Cardiorenal Med 2012;2:328-334 \\
\hline $\begin{array}{l}\text { DOI: 10.1159/000345461 } \\
\text { Published online: November 24, } 2012\end{array}$ & $\begin{array}{l}\text { @ } 2012 \text { S. Karger AG, Basel } \\
\text { www.karger.com/crm }\end{array}$ \\
\hline
\end{tabular}

McFarlane et al.: Bone Mineral Density as a Predictor of Atherosclerosis and Arterial Wall Stiffness in Obese African-American Women

factors. These findings were unchanged upon substitution of femoral neck BMD $\left(p=0.05, R^{2}=\right.$ $0.28)$ into the model. There was a trend with hip BMD $\left(p=0.06, R^{2}=0.28\right)$ in the regression model. Age-matched comparison between normal BMD $(n=25)$ and osteoporotic patients $(n=34)$ demonstrated a significant difference in Al@75 (26.6 \pm 8.9 vs. $31.6 \pm 9.1 \%, p=0.04)$. In summary, women with lower BMD had increased arterial stiffness. There was no relationship between BMD and atherosclerosis. In conclusion, age, hypertension, and BMD are independent predictors of higher arterial stiffness. Vascular changes are related to bone mineral loss, suggesting lower BMD may increase cardiovascular risk in African-Americans.

Copyright $\odot 2012$ S. Karger AG, Basel

\section{Background}

Osteoporosis and osteopenia have been found to be associated with higher cardiovascular event rates, arterial wall calcification, and more extensive atherosclerosis [1-5]. However, the mechanism for this association remains uncertain. Both osteoporosis and atherosclerosis share common risk factors including hypertension, smoking, and sedentary lifestyle [3]. Bone mineral density (BMD) has been found to be inversely correlated with more extensive arterial wall calcification. This has led to the calcium transport hypothesis, in which calcium loss from bone leads to calcium deposition into the arterial wall. Arterial wall calcification would be expected to increase arterial stiffness without affecting subclinical measures of atherosclerosis including carotid intimal-medial thickness (CIMT). Indeed, bone mass loss has been found to be associated with increased arterial stiffness in postmenopausal females and hemodialysis patients [6-8]. Higher arterial stiffness has been found to be a predictor of increased risk for cardiovascular events $[9,10]$. The majority of patients in these studies were Caucasian. African-Americans constitute a minority population in which bone mineral loss is less common and less severe. Moreover, the continuous relationship between BMD and measures of arterial stiffness and atherosclerosis are unknown. Accordingly, the objective of our study was to determine the relationship between BMD, atherosclerosis, and arterial stiffness in African-Americans.

\section{Methods}

Study Subjects

We prospectively studied 100 female patients (age: $63 \pm 14$ years) referred for clinically indicated BMD estimation by dual-energy X-ray absorptiometry (DEXA) scan. Inclusion criteria were: female, age $>18$ years, and adequate radial and carotid pulses to obtain the applanation tonometry study. Patients were excluded if they were unable to give informed consent or were not in sinus rhythm. The risk factors evaluated in this study included age, hyperlipidemia, diabetes mellitus, hypertension, BMI, family history of coronary artery disease, previous stroke, and smoking status. Smokers were defined as patients consuming at least one cigarette daily. Hyperlipidemia, hypertension, and diabetes mellitus were defined either as self-reported, documented diagnosis obtained from chart review, or current treatment with medication.

\section{Measures of Arterial Stiffness}

Arterial stiffness was evaluated by measuring the heart rate-corrected augmentation index (AI@75) and pulse wave velocity (PWV) by applanation tonometry. We used an applanation tonometer interfaced with SphygmoCor software, version 8.0 (AtCor Medical, West Ryde, N.S.W., Australia). The central aortic pressure waveform and AI@75 were derived from the radial artery waveform by means of a validated and population-based generalized transfer function [11]. As the aortic pressure waveform moves to the periphery, the contour changes; thus, the radial artery pressure waveform cannot be used directly, but requires 


\section{CardioRenal Medicine}

\begin{tabular}{l|l}
\hline Cardiorenal Med 2012;2:328-334 \\
\hline DOI: 10.1159/000345461 & $\begin{array}{l}\text { @ 2012 S. Karger AG, Basel } \\
\text { www.karger.com/crm }\end{array}$ \\
Published online: November 24, 2012 &
\end{tabular}

McFarlane et al.: Bone Mineral Density as a Predictor of Atherosclerosis and Arterial Wall Stiffness in Obese African-American Women

a transfer function. The radial artery is easily accessible and supported by bony tissue. This allows the vessel to be flattened with the transmural arterial forces perpendicular to the tonometry probe.AI@75 was defined as the proportional increase in systolic pressure due to the reflected wave and was expressed as a percentage of the pulse pressure. Sequential recordings of arterial pressure waveform at the carotid and radial arteries measured aortic PWV. Distances from the suprasternal notch to the carotid sampling site (distance A) and from the suprasternal notch to the radial artery (distance B) were measured. PWV distance was calculated as distance B minus distance A. Aortic PWV was calculated as the ratio of the distance in meters to the transit time in seconds.

\section{Carotid Intimal-Medial Thickness}

Using a standardized clinical approach, carotid ultrasound was performed using a Phillips SONOS 5500 equipped with a 7.0- to 11.0-MHz high-resolution linear array vascular transducer (Phillips, Andover, Mass., USA). CIMT was defined as the distance from the leading edge of the intima to the leading edge of the media. It was measured over distal $1 \mathrm{~cm}$ of the common carotid artery, just proximal to the bulb on the left and the right side. All of the ultrasonic examinations were stored digitally and CIMT was measured by automated software (QLAB 4.2.1; Philips Ultrasound, IMT Quantification v 1.1).

\section{Bone Mineral Density}

BMD was assessed by DEXA scans. We used Hologic QDR (Delphi A, version 12.0; Holo Inc., USA). BMD $\left(\mathrm{g} / \mathrm{cm}^{2}\right)$ was determined at the lumbar spine (L2-L4), femoral neck, and hip. All patients gave informed consent to participate in the study and the University Hospital of Brooklyn Institutional Review Board approved the study.

\section{Statistical Analysis}

Data are expressed as means \pm SD. Nonparametric Pearson's correlation test was used to evaluate the association between BMD and noninvasive measures of arterial stiffness and atherosclerosis. Student's $t$ test was performed to compare AI@75 in normal and osteoporotic patients. Multiple linear regression analysis was performed to assess the independent predictors of arterial stiffness. All analyses were performed using SPSS, version 15.0 (SPSS, Chicago, Ill., USA). $\mathrm{p}<0.05$ was considered statistically significant.

\section{Results}

Patient baseline characteristics are shown in table 1 . The population was predominantly middle-aged, African-American, and overweight. The mean CIMT, AI@75, and PWV were $0.72 \pm 0.14 \mathrm{~mm}, 28.8 \pm 9.0 \%$, and $8.9 \pm 1.6 \mathrm{~m} / \mathrm{s}$, respectively. The mean BMD at the lumbar spine, femoral neck, and hip were $0.96 \pm 0.19,0.80 \pm 0.16$, and $0.91 \pm 0.17 \mathrm{~g} / \mathrm{cm}^{2}$, respectively. On univariate analysis, older subjects had higher CIMT $(\mathrm{r}=0.61, \mathrm{p}<0.001)$ and AI@75 ( $\mathrm{r}=0.42, \mathrm{p}<0.001)$. There was a significant correlation between AI@75 and CIMT $(\mathrm{r}=0.45, \mathrm{p}<0.001$; fig. 1$)$. AI@75 was directly correlated with PWV $(\mathrm{r}=0.31, \mathrm{p}=0.003)$. No association was found between PWV and BMD. There was no correlation between CIMT and BMD (lumbar spine: $\mathrm{r}=-0.09, \mathrm{p}=0.42$; femoral neck: $\mathrm{r}=-0.15, \mathrm{p}=0.17$; hip: $\mathrm{r}=-0.13$, $\mathrm{p}=0.23$ ). There was a significant negative correlation between AI@75 and BMD (lumbar spine: $\mathrm{r}=-0.24, \mathrm{p}=0.02$; femoral neck: $\mathrm{r}=-0.26, \mathrm{p}=0.01$; hip: $\mathrm{r}=-0.23, \mathrm{p}=0.03$; fig. 1 ).

On multivariate analysis, age $(\mathrm{p}<0.001)$, hypertension $(\mathrm{p}=0.02)$, and lumbar BMD $\left(\mathrm{p}=0.01, \mathrm{R}^{2}=0.30\right)$ were independent predictors of increased AI@75 after adjusting for age, height, and cardiovascular risk factors. These findings were unchanged upon substitution of femoral neck BMD $\left(\mathrm{p}=0.05, \mathrm{R}^{2}=0.28\right)$ into the model. However, there was a trend with hip $\operatorname{BMD}\left(\mathrm{p}=0.06, \mathrm{R}^{2}=0.28\right)$ in the regression model.

In the subset analysis, 25 normal BMD subjects were compared to 34 age-matched osteoporotic subjects ( $63 \pm 15$ vs. $65 \pm 14$ years, $\mathrm{p}=0.54)$. CIMT was similar between the two groups ( $0.77 \pm 0.22$ vs. $0.79 \pm 0.19 \mathrm{~mm}, \mathrm{p}=0.68)$; however, there was a significant difference in AI@75 (26.6 \pm 8.9 vs. $31.6 \pm 9.1 \%, \mathrm{p}=0.04)$. 


\section{CardioRenal \\ Medicine}

\begin{tabular}{l|l}
\hline \multicolumn{2}{l}{ Cardiorenal Med 2012;2:328-334 } \\
\hline $\begin{array}{l}\text { DOI: 10.1159/000345461 } \\
\text { Published online: November 24, } 2012\end{array}$ & $\begin{array}{l}\text { ○ } 2012 \text { S. Karger AG, Basel } \\
\text { www.karger.com/crm }\end{array}$ \\
\hline $\begin{array}{l}\text { McFarlane et al.: Bone Mineral Density as a Predictor of Atherosclerosis and Arterial Wall } \\
\text { Stiffness in Obese African-American Women }\end{array}$
\end{tabular}

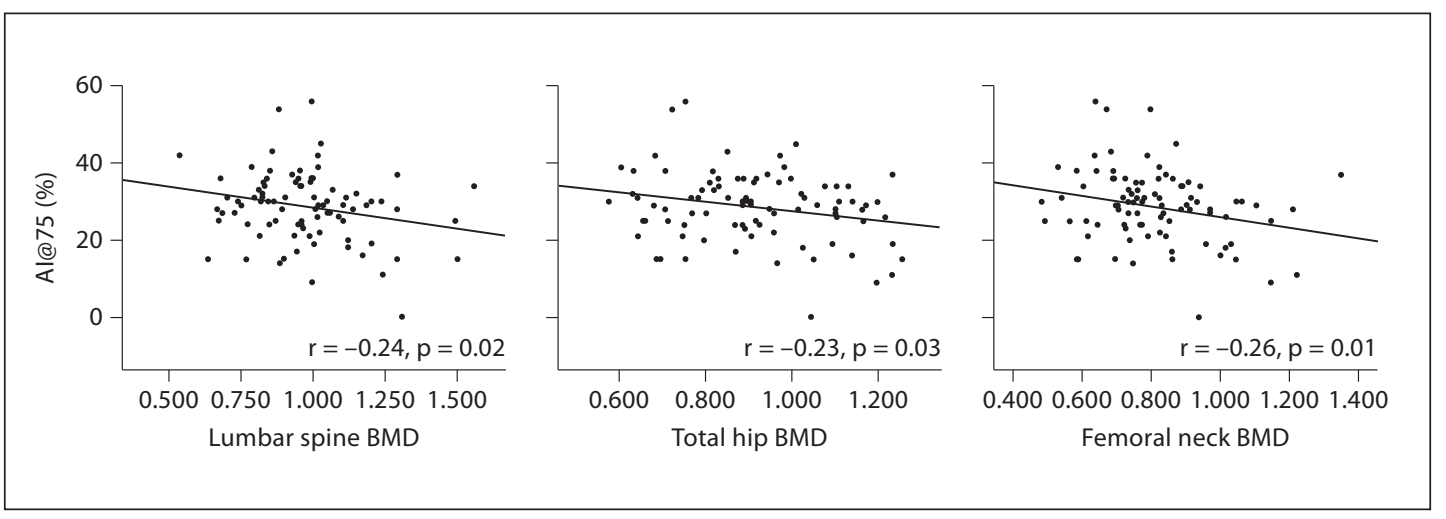

Fig. 1. Relationship between AI@75 and BMD at the lumbar spine, total hip, and femoral neck.

Table 1. Demographic and clinical characteristics

\begin{tabular}{lc}
\hline Variables & Value \pm SD \\
\hline Number & 100 \\
Age, years & $63 \pm 14$ \\
African-American, \% & 87 \\
Weight, kg & $77 \pm 17$ \\
Height, m & $1.6 \pm 0.07$ \\
BMI & $29.6 \pm 6.2$ \\
Hypertension, \% & 70 \\
Hyperlipidemia, \% & 40 \\
Diabetes mellitus, \% & 25 \\
B-Blockers, \% & 35 \\
Statins, \% & 26 \\
ACE inhibitors, \% & 32 \\
Hydrochlorothiazide, \% & 21 \\
Calcium blockers, \% & 21 \\
Smoking, \% & 11 \\
Systolic BP, mm Hg & $137 \pm 20$ \\
Diastolic BP, mm Hg & $83 \pm 10$ \\
Pulse pressure, mm Hg & $54 \pm 16$ \\
Heart rate, bpm & $67 \pm 12$ \\
BMD at the lumbar spine, g/cm ${ }^{2}$ & $0.96 \pm 0.19$ \\
BMD at the femoral neck, g/cm ${ }^{2}$ & $0.80 \pm 0.16$ \\
BMD at the hip, g/cm ${ }^{2}$ & $0.91 \pm 0.17$ \\
CIMT, mm & $0.72 \pm 0.14$ \\
PWV, m/s & $8.9 \pm 1.6$ \\
AI@75, \% & $28.7 \pm 9.0$ \\
&
\end{tabular}

\section{Discussion}

The present study showed that women with lower BMD have a higher AI, suggesting increased arterial stiffness. Age-matched osteoporosis subjects had higher AI when compared to normal BMD subjects, suggesting the relationship between arterial stiffness and bone mineral loss was age independent.

These findings are consistent with previous studies [8, 12]. Mangiafico et al. [8] showed that postmenopausal osteoporotic women had elevated arterial stiffness measured by AI and 


\section{CardioRenal Medicine}

\begin{tabular}{l|l}
\hline Cardiorenal Med 2012;2:328-334 \\
\hline $\begin{array}{l}\text { DOI: 10.1159/000345461 } \\
\text { Published online: November 24, } 2012\end{array}$ & $\begin{array}{l}\text { ○ } 2012 \text { S. Karger AG, Basel } \\
\text { www.karger.com/crm }\end{array}$ \\
\hline $\begin{array}{l}\text { McFarlane et al.: Bone Mineral Density as a Predictor of Atherosclerosis and Arterial Wall } \\
\text { Stiffness in Obese African-American Women }\end{array}$
\end{tabular}

higher central aortic pressures when compared to normal subjects. Sabit et al. [12] reported in COPD patients that AI was associated with BMD measured at the hip but not at the lumbar spine. The association between PWV and BMD measured by DEXA scan showed variable results. Hirose et al. [13] reported that in postmenopausal women, brachial-ankle PWV was negatively related with the osteo-sono index, which reflects BMD measured using calcaneal quantitative ultrasound independent of age and cardiovascular risk factors. In one study, Sumino et al. [6] reported that postmenopausal patients with osteoporosis had higher arterial stiffness measured by brachial-ankle PWV. Mangiafico et al. [8] and Sabit et al. [12] also showed a significant relationship between PWV and bone mineral loss. However, Yamada et al. [14] did not find an independent relationship between lumbar BMD or osteo-sono index and PWV. Similarly, the present study did not demonstrate a correlation between PWV and bone mass loss measured by DEXA scan. This is consistent with a recent study by Toussaint et al. [15] that did not show any correlation between carotid-femoral PWV and spine BMD and femoral neck BMD measured by DEXA scan in hemodialysis patients. Raggi et al. [16] demonstrated that PWV was inversely related to bone density measured by quantitative CT scan rather than by DEXA scan in hemodialysis patients. These findings differed from Joki et al. [7], who showed brachial-ankle PWV was inversely related with BMD and osteo-sono index even in hemodialysis patients. These differences in findings could be explained by different study populations and various PWV measurement methods.

Osteoporosis and cardiovascular diseases increase with age and share common risk factors. The exact mechanism behind the association between BMD and arterial stiffness is not well understood. As described above, women with osteoporosis may have higher risk for cardiovascular events, possibly due to increased calcium efflux from the bone into the vasculature. Oral calcium supplements may also increase vascular calcification. This phenomenon is known as the 'calcium paradox'. There are a number of studies that have shown the association of vascular calcification and bone mineral loss [17, 18]. Estrogen deficiency states such as menopause have been shown in cross-sectional studies to be associated with increased arterial stiffness [19]. Estrogen deficiency is a risk factor for both cardiovascular disease and bone loss. Estrogen receptors have been found on osteoblast, osteoclast, and vasculature cells. Estrogen may be an important factor explaining the link between bone mineral loss and arterial stiffness. However, in the present study, women of all ages were studied, suggesting the association between arterial stiffness and BMD was not dependent on estrogen levels only. The status of menopause and estrogen levels was not recorded in the present study. Decreased nitric oxide levels and increased angiotensin-converting enzyme activity have been found to be associated with increased bone mineral loss. In one study, Sumino et al. [20] demonstrated that postmenopausal women with osteoporosis had impaired vascular endothelial function manifested by decreased flow-mediated dilation in the brachial artery, while Sanada et al. [21] found that postmenopausal women with osteoporosis had decreased forearm blood flow measured by venous plethysmography.

In the present study, atherosclerosis measured by CIMT was not related with increasing bone loss. Studies relating the degree of atherosclerosis and bone mineral loss have shown variable results $[14,22]$. The association between atherosclerosis and bone mineral loss appears to be age dependent. Yamada et al. [14] showed that femoral artery IMT was independently associated with bone strength in the calcaneus but not in the lumbar spine. Kammerer et al. [22] showed that CIMT was associated negatively with BMD in older but not in younger subjects. In another study by Shaffer et al. [23], CIMT was related with BMD in patients older than 60 years but not in subjects younger than 60. Uyama et al. [24] demonstrated the relationship between the presence of carotid plaque and bone mineral loss in postmenopausal women. As our study population consisted of mainly middle-aged subjects, a comparison between younger and older groups was not applicable. 


\section{CardioRenal Medicine}

\begin{tabular}{l|l}
\hline Cardiorenal Med 2012;2:328-334 \\
\hline DOI: $10.1159 / 000345461$ \\
Published online: November 24, 2012 & $\begin{array}{l}\text { @ } 2012 \text { S. Karger AG, Basel } \\
\text { www.karger.com/crm }\end{array}$ \\
\hline
\end{tabular}

McFarlane et al.: Bone Mineral Density as a Predictor of Atherosclerosis and Arterial Wall Stiffness in Obese African-American Women

The present study is unique for two reasons. A high proportion of the study subjects were African-Americans, who are known to have greater cardiovascular risk factors but have slower bone loss and less prevalence of coronary calcium than Caucasians [25-30]. The small number of non-African-Americans did not allow for racial comparisons. In addition, we evaluated the continuous relationship of both functional and anatomical vascular changes with BMD. Other studies have assessed either functional or anatomical changes with bone mineral loss.

\section{Limitations}

There are limitations to this study. The cross-sectional nature of this study allows detection of association, but not cause and effects. PWV was measured between the carotid and radial arteries rather than the femoral artery, which may not represent central aortic stiffness [31]. We did not determine the menopausal status of our subjects with hormonal assay.

\section{Conclusion}

Women with lower BMD had increased arterial stiffness. There was no relationship between BMD and atherosclerosis. Age, hypertension, and BMD are independent predictors of arterial stiffness. These vascular changes may be related to bone mineral loss, suggesting lower BMD may increase cardiovascular risk. Future studies are needed to confirm our findings.

\section{References}

1 Sinnott B, Syed I, Sevrukov A, Barengolts E: Coronary calcification and osteoporosis in men and postmenopausal women are independent processes associated with aging. Calcif Tissue Int 2006;78:195-202.

-2 Bakhireva LN, Barrett-Connor EL, Laughlin GA, Kritz-Silverstein D: Differences in association of bone mineral density with coronary artery calcification in men and women: the Rancho Bernardo Study. Menopause 2005;12:691-698.

-3 Tanko LB, Christiansen C, Cox DA, Geiger MJ, McNabb MA, Cummings SR: Relationship between osteoporosis and cardiovascular disease in postmenopausal women. J Bone Miner Res 2005;20:1912-1920, erratum 2006;21:352.

-4 Marcovitz PA, Tran HH, Franklin BA, O’Neill WW, Yerkey M, Boura J, Kleerekoper M, Dickinson CZ: Usefulness of bone mineral density to predict significant coronary artery disease. Am J Cardiol 2005;96:1059-1063.

5 Farhat GN, Cauley JA, Matthews KA, Newman AB, Johnston J, Mackey R, Edmundowicz D, Sutton-Tyrrell K: Volumetric BMD and vascular calcification in middle-aged women: the Study of Women's Health across the Nation. J Bone Miner Res 2006;21:1839-1846.

-6 Sumino H, Ichikawa S, Kasama S, Takahashi T, Kumakura H, Takayama Y, Kanda T, Sakamaki T, Kurabayashi M: Elevated arterial stiffness in postmenopausal women with osteoporosis. Maturitas 2006;55:212-218.

7 Joki N, Hase H, Shiratake M, Kishi N, Tochigi S, Imamura Y: Calcaneal osteopenia is a new marker for arterial stiffness in chronic hemodialysis patients. Am J Nephrol 2005;25:196-202.

-8 Mangiafico RA, Alagona C, Pennisi P, Parisi N, Mangiafico M, Purrello F, Fiore CE: Increased augmentation index and central aortic blood pressure in osteoporotic postmenopausal women. Osteporos Int 2008;19:49-56.

-9 Pannier BM, Avolio AP, Hoeks A, Mancia G, Takazawa K: Methods and devices for measuring arterial compliance in humans. Am J Hypertens 2002;15:743-753.

10 Willum-Hansen T, Staessen JA, Torp-Pedersen C, Rasmussen S, Thijs L, Ibsen H, Jeppesen J: Prognostic value of aortic pulse wave velocity as index of arterial stiffness in the general population. Circulation 2006;113:664-670.

11 Chen CH, Nevo E, Fetics B, Pak PH, Yin FC, Maughan WL, Kass DA: Estimation of central aortic pressure waveform by mathematical transformation of radial tonometry pressure: validation of generalized transfer function. Circulation 1997;7:1827-1836.

12 Sabit R, Bolton CE, Edwards PH, Pettit RJ, Evans WD, McEniery CM, Wilkinson IB, Cockcroft JR, Shale DJ: Arterial stiffness and osteoporosis in chronic obstructive pulmonary disease. Am J Respir Crit Care Med 2007;175:1259-1265.

13 Hirose K, Tomiyama H, Okazaki R, Arai T, Koji Y, Zaydun G, Hori S, Yamashina A: Increased pulse wave velocity associated with reduced calcaneal quantitative osteo-sono index: possible relationship between atherosclerosis and osteopenia. J Clin Endocrinol Metab 2003;88:2573-2578. 


\section{CardioRenal Medicine}

\begin{tabular}{l|l}
\hline Cardiorenal Med 2012;2:328-334 \\
\hline DOI: 10.1159/000345461 & $\begin{array}{l}\text { @ 2012 S. Karger AG, Basel } \\
\text { www.karger.com/crm }\end{array}$ \\
\hline Published online: November 24, 2012 &
\end{tabular}

McFarlane et al.: Bone Mineral Density as a Predictor of Atherosclerosis and Arterial Wall Stiffness in Obese African-American Women

- 14 Yamada S, Inaba M, Goto H, Nagata M, Ueda M, Nakatuka K, Tahara H, Yokoyama H, Emoto M, Shoji T, Nishizawa Y: Significance of intima-media thickness in femoral artery in the determination of calcaneus osteo-sono index but not of lumbar spine in healthy Japanese people. Osteporos Int 2005;16:64-70.

$\longrightarrow 15$ Toussaint ND, Lau KK, Strauss BJ, Polkinghorne KR, Kerr PG: Associations between vascular calcification, arterial stiffness and bone mineral density in chronic kidney disease. Nephrol Dial Transplant 2008;23:586-593.

16 Raggi P, Bellasi A, Ferramosca E, Block GA, Muntner P: Pulse wave velocity is inversely related to vertebral bone density in hemodialysis patients. Hypertension 2007;49:1278-1284.

17 McFarlane SI, Muniyappa R, Shin JJ, Bahtiyar G, Sowers JR: Osteoporosis and cardiovascular disease: brittle bones and boned arteries, is there a link? Endocrine 2004;23:1-10.

18 Reddy J, Bilezikian JP, Smith SJ, Mosca L: Reduced bone mineral density is associated with breast arterial calcification. J Clin Endocrinol Metab 2008;93:208-211.

19 Zaydun G, Tomiyama H, Hashimoto H, Arai T, Koji Y, Yambe M, Motobe K, Hori S, Yamashina A: Menopause is an independent factor augmenting the age-related increase in arterial stiffness in the early postmenopausal phase. Atherosclerosis 2006;184:137-142.

-20 Sumino H, Ichikawa S, Kasama S, Takahashi T, Sakamoto H, Kumakura H, Takayama Y, Kanda T, Murakami M, Kurabayashi M: Relationship between brachial arterial endothelial function and lumbar spine bone mineral density in postmenopausal women. Circ J 2007;71:1555-1559.

-21 Sanada M, Taguchi A, Higashi Y, Tsuda M, Kodama I, Yoshizumi M, Ohama K: Forearm endothelial function and bone mineral loss in postmenopausal women. Atherosclerosis 2004;176:387-392.

-22 Kammerer CM, Dualan AA, Samollow PB, Perisse AR, Bauer RL, MacCluer JW, O’Leary DH, Mitchell BD: Bone mineral density, carotid artery intima medial thickness, and the vitamin D receptor Bsml polymorphism in Mexican American women. Calcif Tissue Int 2004;75:292-298.

23 Shaffer JR, Kammerer CM, Rainwater DL, O’Leary DH, Bruder JM, Bauer RL, Mitchell BD: Decreased bone mineral density is correlated with increased subclinical atherosclerosis in older, but not younger, Mexican American women and men: the San Antonio Family Osteoporosis Study. Calcif Tissue Int 2007;81:430-441.

24 Uyama O, Yoshimoto Y, Yamamoto Y, Kawai A: Bone changes and carotid atherosclerosis in postmenopausal women. Stroke 1997;28:1730-1732.

25 George A, Tracy JK, Meyer WA, Flores RH, Wilson PD, Hochberg MC: Racial differences in bone mineral density in older men. J Bone Miner Res 2003;18:2238-2244.

26 Cauley JA, Lui LY, Ensrud KE, Zmuda JM, Stone KL, Hochberg MC, Cummings SR: Bone mineral density and the risk of incident nonspinal fractures in black and white women. JAMA 2005;293:2102-2108.

27 Bell NH, Gordon L, Stevens J, Shary JR: Demonstration that bone mineral density of the lumbar spine, trochanter, and femoral neck is higher in black than in white young men. Calcif Tissue Int 1995;56:11-13.

28 Newman AB, Naydeck BL, Whittle J, Sutton-Tyrell K, Edmundowicz D, Kuller LH: Racial differences in coronary artery calcification in older adults. Arterioscler Thromb Vasc Biol 2002;22:424-430.

29 Tang W, Detrano RC, Brezden OS, Georgiou D, French WJ, Wong ND, Doherty TM, Brundage BH: Racial differences in coronary calcium prevalence among high-risk adults. Am J Cardiol 1995;75:1088-1091.

30 Lee TC, O’Malley PG, Feuerstein I, Taylor AJ: The prevalence and severity of coronary artery calcification on coronary artery computed tomography in black and white subjects. J Am Coll Cardiol 2003;41:39-44.

31 Nichols WV, O’Rourke MF: McDonald's Blood Flow in Arteries. Theoretical, Experimental and Principles, ed 5. London, Hodder Arnold, 2005, pp 165-191. 